\title{
A concepção teórico-política do projeto Future-se e a concepção de internacionalização da educação
}

\section{The theoretical-political conception of the Future-se project and the conception of the internationalization of education}

\section{La concepción teórico-política del proyecto Future-se y la concepción de la internacionalización de la educación}

Tânia Martins ${ }^{1}$

Sylvia Cristina de Azevedo Vitti ${ }^{2}$

RESUMO: O objetivo do artigo é apresentar o Programa Institutos e Universidades Empreendedoras e Inovadoras (Future-se) e a sua concepção de internacionalização da educação. O plano de trabalho incluiu analisar os eixos do projeto de lei, considerando os artigos da área do ensino superior e das entidades educacionais. Conclui-se que o Future-se tem uma visão míope e estreita de internacionalização da educação, como estratégia para promover uma privatização indireta das instituições de ensino superior, legitimando-se pelo discurso da integração ao mercado internacional.

Palavras-chave: Future-se. Educação Superior. Internacionalização da Educação.

ABSTRACT: The objective of the article is to present the Entrepreneurial and Innovative Institutes and Universities Program (Future-se) and its conception of the internationalization of education. The work plan included analyzing the axes of the draft law, considering articles in higher education and educational entities. It is concluded that Future-se has a short-sighted and narrow vision of the internationalization of education, as a strategy to promote an indirect privatization of higher education institutions, legitimizing itself through the discourse of integration into the international market.

Keywords: Future-se. Higher education. Internationalization of Education.

\footnotetext{
${ }^{1}$ Universidade Metodista de Piracicaba.

E-mail: taniabmartins@yahoo.com.br | ORCID: https://orcid.org/0000-0003-4095-4995

${ }^{2}$ Faculdade de Tecnologia de Piracicaba.

E-mail: vittisylvia@gmail.com | ORCID: https://orcid.org/0000-0002-1050-9228
} 
RESUMEN: El objetivo del artículo es presentar el Programa de Institutos y Universidades Emprendedoras e Innovadoras (Future-se) y su concepción de la internacionalización de la educación. El plan de trabajo incluyó analizar los ejes del proyecto de ley, considerando artículos en el área de educación superior y entidades educativas. Se concluye que Future-se tiene una visión miope y estrecha de la internacionalización de la educación, como estrategia para promover una privatización indirecta de las instituciones de educación superior, legitimándose a través del discurso de integración en el mercado internacional.

Palabras clave: Future-se. Educación universitaria. Internacionalización de la educación. 
O Programa Institutos e Universidades Empreendedoras e Inovadoras - Future-se, proposto pelo Ministério da Educação (MEC) no atual governo Bolsonaro (20192022), foi lançado em 17 de julho de 2019 pelo ministro da educação Abraham Weintraub. O programa foi apresentado a reitores das Universidades e Institutos Federais pelo secretário de educação Arnaldo Lima. O anteprojeto de lei do programa é o documento que tem sido utilizado por universidades, entidades relacionadas ao ensino superior, dentre outras, para análise e posicionamento da comunidade acadêmica frente à proposta do Future-se.

O Future-se permaneceu aberto durante alguns períodos para consulta pública. Segundo o MEC a consulta pública tinha como intenção reunir contribuições a fim de aperfeiçoar o programa e possibilitar que o documento fosse mais bem compreendido pelos cidadãos brasileiros interessados em analisar o texto e fazer contribuições (Brasil, 2019b). Era a intenção do MEC enviar o projeto ao Congresso ainda em 2019, porém isto não ocorreu. A propósito, indaga-se sobre as razões do programa e o projeto de lei não ter seguido os encaminhamentos protocolares democráticos. Cabe considerar, que depois de várias consultas, debates e ações jurídicas contrárias ao projeto, ele foi encaminhando ao Congresso, de forma sutil, quase que como uma nota de rodapé, em 03 de janeiro de 2020. Ainda que o MEC, defenda o diálogo e a apresentação de sugestões vindas das universidades e institutos federais brasileiros, o processo de elaboração do projeto Future-se em si não permite oposição tampouco negação. Aliás, é recorrente consultas públicas se apresentarem enviesadas, sem respaldo conjuntural e da história, e desconsiderando efetivamente os posicionamentos dos sujeitos mais interessados.

A adesão ao projeto é considerada voluntária, um voluntário cujas consequências aos que não aderirem seria a insegurança institucional da Universidade e Instituto Federal, quanto ao financiamento estatal. Daí que somente as instituições interessadas nas propostas apresentadas pelo Future-se seriam incluídas no programa. Segundo o MEC, a União iria manter os recursos destinados às instituições, sendo considerados recursos extras os que se originarem do Future-se, parecendo uma política de "primeiro infiltrar-se, depois modificar".

De acordo com o MEC, o programa Futurese objetiva ampliar a autonomia financeira das universidades $e$ institutos federais (IFES), por meio do fomento ao empreendedorismo e à inovação, favorecendo a captação de recursos próprios nos setores privados. Tal intento se daria por meio de contratos de gestão da União e das IFES com as chamadas organizações sociais (O.S.) relacionadas ao ensino, pesquisa científica, desenvolvimento tecnológico e à cultura, em sintonia com os objetivos do Future-se. 
O Future-se enfrenta resistência por parte das universidades federais e membros da academia. Há críticas que apontam a falta de diagnóstico da realidade das IFES e ausência de uma consulta prévia à comunidade. O seu conteúdo é objeto de rejeição, os críticos enxergam o Future-se com um grave ataque às universidades $e$ institutos federais, à sua autonomia e aos direitos dos servidores, especialmente dos docentes: condição trabalhista, condições de trabalho, condições acadêmicas, liberdade de cátedra etc. Há críticas com relação à submissão do ensino, pesquisa $\mathrm{e}$ extensão a interesses imediatos voltados para a lucratividade, assim como a gestão universitária de tais instituições feita por organizações sociais de propriedade privada, vinculados à lógica do capital.
Portanto, afirmam que o Future-se desmantelaria 0 projeto de governos anteriores, no sentido de expandir e democratizar o acesso das classes menos favorecidas (Taffarel \& Sousa, 2019).

Assim sendo, o objetivo deste artigo é tratar do programa Future-se, elaborado pelo MEC, considerando suas três versões, com destaque para algumas ponderações institucionais e posicionamentos de intelectuais que trataram do Future-se. A intenção maior é compreender a concepção de educação superior com o Future-se, especificamente, a dimensão da "internacionalização" que se apresenta de maneira bastante ampla e difusa.

\section{O Programa Future-se em sua primeira versão}

De acordo com o portal do MEC (Brasil, 2019b), o Future-se, lançado oficialmente em 17 de julho de 2019, "busca o fortalecimento da autonomia administrativa, financeira e da gestão das universidades e institutos federais". As ações serão implementadas por parcerias com organizações sociais, as O.S, sendo orientadas por meio de três eixos, a saber: 1) Gestão, Governança e Empreendedorismo; 2) Pesquisa e Inovação e 3) Internacionalização.

O primeiro eixo, Gestão, Governança e Empreendedorismo, tem como intuito promover a sustentabilidade financeira, ao estabelecer um limite de gasto com pessoal nas universidades e institutos federais e estabelecer requisitos de transparência, auditoria externa, dentre outros. Prevê a criação de ranking das instituições, premiando aquelas que se mostrarem mais eficientes na gestão de seus gastos. Engloba a questão da gestão imobiliária, que estimula o uso de imóveis da União para arrecadar recursos por meio de contratos de cessão de uso, concessão, fundo de investimento, parcerias públicoprivadas (PPPs) e estimula o compartilhamento de conhecimento entre departamentos de universidades e institutos, incentivando-os na busca de arrecadação de recursos próprios na iniciativa privada. Além disso, propõe o naming rights, o que, inclusive, daria o direito às empresas, patrocinadores e patronos da instituição universitária de colocar seus nomes nos campi e em edifícios, em apoio à contribuição na 
manutenção e na modernização dos equipamentos com 0 apoio do setor privado.

O segundo eixo, Pesquisa e Inovação, prevê a instalação de centros de pesquisa e inovação, assim como de parques tecnológicos, além de favorecer a criação de empresas de bases tecnológicas. Este eixo tem como objetivo aproximar as instituições de ensino e as empresas, a fim de facilitar a captação de recursos privados, além de premiar projetos inovadores, principalmente em instituições com bom desempenho.

O terceiro e último eixo, Internacionalização, tem como foco estimular o intercâmbio de estudantes e professores que desenvolvam pesquisa aplicada; visa revalidar títulos e diplomas estrangeiros por instituições de alto desempenho acreditadas pelo MEC e procura estimular a promoção de disciplinas on-line e a publicação de periódicos fora do país por meio de parcerias com entidades privadas. Por fim, prevê a concessão de bolsas de estudos no exterior a estudantes com alto desempenho acadêmico e atlético. De certa forma, está implícita uma perspectiva de atrelar os interessas das universidades e institutos federais a interesses internacionais.

O MEC enfatiza que o Future-se permitiria às IFES o aumento de suas receitas pela captação de recursos próprios no setor privado e estimular a flexibilidade na gestão de suas despesas. Com isso, as IFES dependeriam menos do orçamento da União. Trata-se, portanto, de uma proposta não convencional considerando o histórico da administração do ensino superior público brasileiro, com destaque para a contratação de O.S., além do fomento de financiamento privado. A captação de recursos próprios e privados, conforme mencionado anteriormente, ocorreria mediante contratos de gestão da União e das instituições federais com O.S. diretamente relacionadas ao ensino, pesquisa científica, desenvolvimento tecnológico e à cultura, em sintonia com os objetivos do Future-se. Faz-se necessário esclarecer que uma O.S., no entendimento do MEC, "é uma associação privada que recebe recursos do Estado para prestar serviço de interesse público, como saúde e educação" (Brasil, 2019b), o que corresponde à transferência de recursos públicos para o setor privado. Ainda de acordo com o Portal do MEC, os contratos de gestão poderão ser celebrados com O.S. já qualificadas pelo MEC ou por outros ministérios, sem a necessidade de chamamento público, contanto que o escopo do trabalho esteja no âmbito dos contratos de gestão já existentes.

O Future-se, é uma proposta governamental, que entre outras políticas, cria um fundo de natureza privada para financiar as IFES, apelidado de Fundo Soberano do Conhecimento, uma espécie de um fundo de direito privado que, no discurso oficial, aumenta a autonomia financeira das instituições federais de ensino. Cabe considerar, entretanto, que a administração do fundo passaria a ser de responsabilidade de uma instituição financeira privada (Brasil, 2019a).

O Future-se gerou inúmeras críticas no âmbito acadêmico, uma vez que muitos reitores julgaram o texto pouco detalhado. A maior preocupação girou em torno da 
autonomia das instituições. De acordo com publicação do Sindicato Nacional dos Servidores Federais da Educação Básica, Profissional e Tecnológica Sul-riograndense (SINASEFE IFSul, 2019), a consulta pública encerrada no dia 29 de agosto de 2019, registrou milhares de inscrições e o projeto recebeu $20 \mathrm{mil}$ contribuições. Em outubro de 2019, um anteprojeto do Future-se reformulado por especialistas jurídicos do MEC foi reelaborado e submetido a uma nova consulta pública, para só então ser encaminhado ao Congresso Nacional. Segundo Moreno (2019), o novo documento oficial do Future-se foi reformulado em três meses após de seu lançamento.

\section{O Programa Future-se em sua segunda versão}

Moreno (2019) analisou as principais mudanças entre a primeira e a segunda versão do Future-se, esta última considerada mais enxuta. Na primeira delas, o programa era estruturado em três eixos. A nova versão mantém os três eixos, mas altera sua ordem, retirando ainda as menções aos termos governança e gestão. No novo texto, os eixos apresentam-se da seguinte maneira: 1) Pesquisa, desenvolvimento tecnológico e inovação; 2) Empreendedorismo e 3) Internacionalização (que se mantem firme).

$\mathrm{Na}$ primeira versão, apenas O.S. foram citadas como sendo as entidades privadas com fins sociais aptas a participarem do Future-se. Nesta primeira versão, apenas O.S. qualificadas pelo MEC e pelo Ministério da Ciência e Tecnologia (MCTIC) poderiam participar. Além destas organizações, outras entidades que também poderiam ser criadas eram as Sociedades de Propósito Específico e as startups. A proposta reformulada inclui as Fundações de Apoio como alternativa às O.S., para fazerem a intermediação entre as instituições de ensino e a sociedade no desenvolvimento de projetos no âmbito da ciência e tecnologia.

Outra mudança apontada por Moreno (2019) é que na primeira versão, os contratos de gestão seriam firmados entre a União e cada instituição com uma ou mais O.S., sem definir quantas. Já na segunda versão, consta que a União estabeleceria um contrato, contendo uma série de metas, com cada instituição. $\mathrm{Na}$ primeira versão do Future-se constava que a adesão ao programa ocorreria de forma voluntária pela instituição universitária e não haveria graus variados de participação. A adesão pressupunha que as instituições participantes passariam a se submeter às diretrizes definidas por um comitê gestor que, inclusive, definiria os critérios para docentes se candidatarem à posição de reitor. A nova versão divulgada em outubro não menciona mais o comitê em questão, sendo que os elementos do contrato passariam a ser definidos conjuntamente entre a instituição universitária e a União, por intermédio do MEC.

A primeira versão menciona um fundo para permitir o aumento da autonomia 
financeira das instituições federais de ensino superior, incentivando a prática de naming rights, criação de fundos de patrimônio, entre alternativas de complementação de orçamento. O MEC ainda sugere que hospitais universitários atendam pacientes que possuíam planos privados de saúde. Na versão reformulada, a possibilidade de atendimento de pacientes particulares por hospitais universitários foi extinta, embora os fundos de financiamento - Fundo Patrimonial do Future-se e o chamado Fundo Soberano do Conhecimento - tenham sido mantidos.

Segundo Moreno (2019), o texto inicial do Future-se previa a alteração de 17 leis, tais como as Leis $n^{\circ}$ 9.637/1998, $n^{\circ} \quad 10.973 / 2004, \quad n^{\circ} \quad 13.243 / 2016$, $\mathrm{n}^{\circ} \quad 9.394 / 1996, \quad \mathrm{n}^{\circ} \quad 8.313 / 1991$, $n^{\circ} 10.735 / 2003$, dentre outras, que no segundo texto passaram a ser 15 , o que inclui a Lei de Diretrizes e Bases da Educação Nacional (LDB). Porém, quatro leis que seriam previamente alteradas (as Leis $n^{\circ}$ 12.772/2012, $n^{\circ}$ 9.637/1998, $\mathrm{n}^{\circ} 11.196 / 2005$ e $\left.\mathrm{n}^{\circ} 12.550 / 2011\right)$ deixaram de ser, sendo que duas outras (Leis $n^{\circ} 11.091 / 2005$ e $n^{\circ} 13.800 / 2019$ ), não constantes do primeiro documento, entraram no texto reformulado. Agora então serão 13 leis a serem alteradas e um artigo da LDB relativo às instituições privadas de ensino superior. Especificamente, em se tratando da internacionalização à validação de diplomas estrangeiros de ensino superior por instituições universitárias brasileiras públicas e privadas, de alto desempenho, manteve-se na segunda versão (Moreno, 2019).

\section{O Programa Future-se em sua terceira versão}

No dia 3 de janeiro de 2020, o MEC, por meio da casa civil, publicou uma nova versão do programa Future-se no Diário Oficial da União, em forma de Projeto de Lei. O novo texto ficou em consulta pública até o dia 24 de janeiro e, ainda não teve um desfecho. A terceira versão do Futurese no artigo 1 destaca como objetivo:

I - incentivar fontes privadas adicionais de financiamento para projetos e programas de interesse de universidades e institutos federais;

II - promover e incentivar o desenvolvimento científico, a pesquisa, a capacitação científica e tecnológica e a inovação;
III - fomentar a cultura empreendedora em projetos e programas destinados ao ensino superior;

IV - estimular a internacionalização das universidades e dos institutos federais; e

$\mathrm{V}$ - aumentar as taxas de conclusão e os índices de empregabilidade dos egressos de universidades e institutos federais

(Brasil, 2020)

A estrutura da terceira versão apresenta os mesmos eixos da segunda versão 1) Pesquisa, desenvolvimento tecnológico e inovação; 2) Empreendedorismo e 3) Internacionalização, inclusive, as pequenas alterações não comprometem as intenções do MEC, ou seja, de criar um novo arcabouço jurídico, que a despeito 
das supostas boas intenções, destina-se à suprimir a autonomia universitária, promovendo a privatização contínua e direta das IFES com a introdução de uma cultura mercantil no interior das instituições. Cabe mencionar que vários dispositivos do Future-se já constavam no Marco Regulatório da Ciência e Tecnologia, com a aprovação em 26 de fevereiro de 2015 da Emenda Constitucional $n^{\circ} 85$, em 11 de janeiro de 2016 da Lei $n^{\circ} 13.243$ e em 7 de fevereiro de 2018, do Decreto $n^{\circ} 9.283$, e que estabelece uma relação próxima entre universidade e institutos federais com a iniciativa privada, nos projetos de ensino e pesquisa, tornando o Future-se desnecessário em muitas situações.

A terceira versão do projeto Future-se apresenta um vocabulário com bastantes termos e expressões novas, que exigirá explicação no próprio Projeto de Lei. Destacam-se com base no Art. 30: Contrato de resultado, benefícios por resultado, indicadores de resultado, fundação de apoio, organização social, contrato de concessão de direito de nomear (naming rights), Sociedade de Propósito Específico, start-up, dentre outros. Assim sendo, a apreciação da terceira versão do Future-se em relação às versões anteriores mostra que os fundamentos políticos e econômicos dos projetos são semelhantes e se mantem firmes, de modo que, em todas as versões, ainda com as supressões e/ou adição de algum elemento, há uma clara concepção de educação superior orientada para e com o mercado e o setor produtivo e financeiro do mercado, com destaque o desenvolvimento de uma cultura empreendedora e com implicações diretas na dimensão internacional da educação.

\section{posicionamento de intelectuais e entidades da educação}

Em uma análise preliminar feita pela Universidade Federal de Pelotas (UFPel, 2019), o MEC fez o lançamento do Futurese oficialmente em 17 de julho de 2019, o que causou um estranhamento, uma vez que as instituições de ensino superior que seriam afetadas pelo programa não foram chamadas a colaborar com a elaboração da proposta, recebendo de forma abrupta a notícia. De acordo com a análise da UFPel, esta foi uma falha grave desde o início e pressupõe que a não convocação das IFES, representadas por seus reitores, tenha sido proposital. $\mathrm{O}$ mesmo documento também critica a pressa no cronograma apresentado pelo MEC, uma vez que a análise da UFPel julga que o Future-se deveria ser discutido de forma mais pormenorizada com as universidades e seus representantes, por meio do diálogo. O período de consulta pública também foi criticado por ser muito curto, de apenas três semanas, para posteriormente ser estendido para quatro semanas.

$\mathrm{Na}$ nota disponibilizada pela Associação Nacional de Pós-Graduação e Pesquisa em Educação (ANPED) em 2019, há menção sobre a incerteza e o futuro da educação superior no país, além da crítica de que o projeto não solucionaria os problemas que as universidades 
enfrentam relacionadas ao acesso ao ensino superior, à expansão de vagas de graduação e pós-graduação, à inclusão e permanência no ensino superior, que fazem parte das metas do PNE. Outro ponto abordado pelo documento da ANPED (2019) é o fato de que as O.S. irão se envolver diretamente em atividades-fim nas instituições de ensino, e o interesse estaria focado em pesquisas que possibilitem retorno financeiro. Não há menção a atividades que envolvam o ensino e a extensão. Segundo o documento, a única referência apresentada pelo Future-se ao ensino é sugestão da cobrança de mensalidade para cursos de especialização lato sensu. A ANPED acredita que o Future-se carece de estudos sobre a melhoria da educação superior brasileira e que está focado na eficácia gerencial do setor privado menosprezando a dimensão pública da educação.

Nessa perspectiva, tanto a Associação Nacional dos Dirigentes das Instituições Federais de Ensino Superior (ANDIFES) quanto $O$ Conselho Nacional das Instituições da Rede Federal de Educação Profissional, Científica e Tecnológica (CONIF) se pronunciaram externado preocupação em relação ao Future-se. Em nota oficial o CONIF, publicada em agosto de 2019, o conselho levantou alguns pontos sobre a questão, destacando à exclusão dos agentes públicos, dirigentes e representantes das instituições federais na construção e no debate acerca do projeto Future-se. A ANDIFES divulgou uma lista de manifestações apresentadas pelas universidades brasileiras e criou um grupo de estudos do Future-se, além de publicar uma nota de rejeição (ANDIFES, 2019), destacando a forma aligeirada, superficial e inoportuna do programa Future-se. O CONIF refere-se à superficialidade com que o texto do Futurese trata conceitos sedimentados constitucionalmente como autonomia da gestão institucional, com as organizações sociais e fundos de investimento, elementos estranhos ao universo acadêmico. O CONIF posiciona-se pela garantia da educação pública e gratuita, direito de todos os brasileiros, e ao papel do Estado como provedor e mantenedor destas funções. O CONIF defende as políticas que visam assegurar o papel da União como provedor do direito constitucional à educação.

Baima (2019), em seu texto "Future-se: Destruição do Ensino Superior", acredita que o Future-se é um programa de privatização das instituições federais, incluindo as universidades, institutos federais e Centros Federais de Educação Tecnológica. A transferência da gestão das instituições públicas para O.S., alteraria as personalidades jurídicas das instituições federais de ensino superior, sendo que passariam a ser públicas, de direito privado. Isto, segundo Baima (2019), possibilitaria a alienação do patrimônio destas instituições, a contratação de docentes e pessoal técnico sem a necessidade de concurso público, o incentivo aos projetos privados e ao empreendedorismo, além da implementação de mecanismos de premiação. $O$ autor se refere à subordinação da produção intelectual à possibilidade de comercialização, uma vez que passaria a ser dependente de 
resultados do mercado. Assim sendo, Baima (2019) acredita que o Future-se visa extinguir a autonomia administrativa das instituições federais, por meio da introdução de gestores executivos, e considera o maior ataque ao ensino superior público nacional.

Dagnino, Romao e Bezerra (2019) também se mostram críticos ao Future-se, que, a seu ver, tem a intenção de solucionar o que considera o principal problema das instituições federais de ensino superior, seu custo para o Estado. Esta solução se daria por meio da captação de recursos das empresas para pesquisa $e$ desenvolvimento, uma vez que se estabeleceriam parcerias com as empresas proporcionando às instituições federais o acesso a recursos privados para inovação por meio de projetos.

Dagnino et al. (2019) julgam que a importância da pesquisa universitária para a empresa é muito pequena, não só no Brasil, mas a nível mundial. Eles fundamentam esta afirmação com base na realidade norte-americana, por meio da qual observa-se que apenas $1 \%$ é a parcela gasta por empresas parceiras em pesquisas conduzidas em universidades e institutos de pesquisa. Para os autores, a realidade brasileira é semelhante à americana no que diz respeito ao baixo interesse de empresas em realizar parcerias para pesquisa e desenvolvimento com universidades. Eles citam o caso da Universidade Estadual de Campinas (Unicamp), para a qual os recursos para pesquisa provenientes de empresas representam menos de $1,5 \%$ no seu orçamento. Ainda segundo Dagnino et al. (2019), o conhecimento resultante da pesquisa universitária, incorporado aos graduados brasileiros é pouco relevante para as empresas, sendo que, ao contrário do que ocorre nos EUA, poucos aqui são contratados pelas empresas para as áreas de pesquisa e desenvolvimento. Os autores finalizam seu texto enfatizando a pouca viabilidade que o Future-se poderia ter na mudança das relações entre empresas e instituições de ensino superior no quesito pesquisa e desenvolvimento.

Nesse sentido, uma das observações feitas por Leher (2019) é a de que as propostas não contêm referências $e$ estudos de viabilidade para torná-lo inteligível. Em sua compreensão sobre o que diz o programa a respeito de tornar as instituições federais inovadoras e integradas ao mercado, acredita que está subentendido que as instituições que não aderirem ao Future-se estarão fadadas ao fracasso, por perderem "o bonde da história". Ele ainda salienta que o programa pretende se legitimar por meio de experiências conduzidas em universidades de outros países, considerados "avançadas".

Leher (2019) afirma que a amplitude das mudanças nas leis preconizadas pelo Future-se é extensa. $\mathrm{O}$ autor considera que o texto foi mal elaborado para então ser disponibilizado para a consulta pública, sendo que não aborda questões como a problemática da pesquisa $e$ desenvolvimento ou a grave crise de financiamento do sistema federal de educação, mas, mesmo assim, sugere uma reforma universitária em consonância com o modelo econômico liberalizante vigente no país. De acordo com Leher (2019), temas de grande importância, que 
inclusive, envolvem à dimensão da internacionalização, são abordados de modo superficial pelo Future-se o que sugere que seu objetivo seria o de instituir um choque de neoliberalismo nas instituições federais.

Para Leher (2019), o projeto não tem como meta fortalecer a inovação tecnológica no país, como preconiza o eixo Inovação, Pesquisa e Desenvolvimento. Argumenta que os termos Inovação, Pesquisa e Desenvolvimento não estão conceituados no projeto, enquanto o termo "inovação" associado a "contratos de gestão" estabelece a ideia de pesquisa inscrita no ambiente de negócios, com fins utilitaristas.

Segundo Leher (2019), o projeto agrava os problemas já vivenciados pelas instituições federais no que diz respeito à pesquisa $e$ desenvolvimento. Outras questões preocupantes são as alterações na autonomia da gestão financeira das instituições, substituindo as obrigações do Estado, a implantação de metas e indicadores de governança para instituições participantes do Future-se, a instauração de parcerias público-privadas nos moldes empresariais, as mudanças na natureza do trabalho docente, a possibilidade da internacionalização da educação como mercadoria e as mudanças que poderão surgir no campo da saúde.

A Rede Brasil Atual (RBA), em uma matéria publicada no dia 5 de novembro de 2019, trouxe trechos da audiência ocorrida no Senado em 04/11/2019, onde representantes da educação expuseram suas visões sobre o Future-se. Segundo os participantes da audiência pública, o programa fere o princípio da autonomia universitária previsto na Constituição Federal Brasileira. De modo geral, na referida matéria, os representantes da educação, entre os quais Jacqueline Rodrigues de Lima, segunda secretária do Sindicato Nacional dos Docentes das Instituições de Ensino Superior (ANDES), Nelson Cardoso Amaral, conselheiro titular da Associação Nacional de Pesquisa em Financiamento da Educação (Fineduca) e Antônio Alves Neto, coordenador-geral da Federação de Sindicatos de Trabalhadores Técnico-Administrativos em Instituições de Ensino Superior Públicas do Brasil (Fasubra), argumentam que a universidade pública é responsável por $60 \%$ da pesquisa desenvolvida no Brasil e que a parceria com empresas não é novidade e nem ausente nas universidade e institutos federais. Sendo assim, as propostas do Future-se são ações que já ocorrem no âmbito das universidades.

Segundo representantes da educação, este programa, na visão dos participantes da audiência pública, não valoriza as diferenças regionais, uma vez que submete as universidades federais a um processo unificado de educação. Além disso, criticaram o Future-se por promover a mercantilização da educação, tratando-a serviço e não direito social.

Tendo isso em vista, cabe considerar o grande impacto do Future-se na identidade das universidades $e$ institutos federais brasileiros decorrentes da tentativa de reformular os investimentos nas instituições federais de ensino superior. A apreciação do Future-se, assim como dos vários posicionamentos, mostra que de 
fato a intenção é para além de diminuir a parcela de recursos proveniente da União e ampliar a captação de recursos privados, é promover a submissão e controle das atividades nas instituições federais pelas empresas privadas. Dessa forma, pesquisadores de determinas áreas vão se aproximar de interesses privados e usar parte de seu tempo para se dedicar a atividades de interesse das empresas.

A propósito dos Fundos Patrimoniais, não se pode ignorar sua natureza estritamente mercantil e sua vinculação às vicissitudes próprias dos voláteis mercados financeiros. Daí que o Future-se, representa muito mais a lógica agressiva das reformas neoliberais pensadas para a América Latina, desde meados da década de 1990, convertendo os sistemas educacionais em nichos de mercado. Nessa perspectiva, é necessário que o setor público seja precarizado, sucateado e privatizado para que a lógica mercantil e financeira se operacionalize em detrimento da defesa da educação pública.

Vale ressaltar que, apesar dos vários posicionamentos acerca do que está ocorrendo, nem todas as entidades ligadas à educação mostram-se contrárias ao Future-se. Segundo texto de Marques (2019), dia 17 de setembro de 2019, representantes da Academia Brasileira de Educação (ABE) encontraram-se com o ministro da educação para prestar apoio ao Future-se. O grupo era composto de exreitores da Universidade Federal Fluminense (UFF) e da Pontifícia Universidade Católica do Rio de Janeiro (PUC-RJ), representando a Academia e demonstrando irrestrito apoio ao programa do MEC.

O presidente da $A B E$, Carlos Alberto Serpa, afirma que o sistema federal de educação superior no Brasil requer mudanças e enfatiza a necessidade de menos burocracia. Serpa afirmou que "Na qualidade de presidente da Academia, trouxemos ao ministro o apoio formal ao Future-se. A Academia coloca-se à disposição para mediar situações que sejam necessárias para que o projeto dê certo" (Marques, 2019).

Serpa é ex-reitor da PUC-RJ e acredita que o apoio da iniciativa privada a questão orçamentária das IFES pode vir a melhorar e que a pesquisa aplicada no país pode auxiliar ao desenvolvimento científico e tecnológico. A mesma visão otimista é compartilhada por Sidney Mello, integrante da ABE e ex-reitor da UFF.

Cabe considerar que os posicionamentos a favor do Future-se provenientes do ambiente acadêmico são pontuais em relação ao conjunto de posicionamentos e ações contrárias no país.

\section{A concepção de Internacionalização no Future-se}

A internacionalização apresenta-se como um dos eixos do projeto Future-se, no entanto, de modo geral, há uma compreensão bastante reducionista de internacionalização. A primeira versão do Future-se, composta por dois únicos artigos, limita-se à sua operacionalização à cursos de idiomas, intercâmbio entre 
universidades nacionais e internacionais, oferta de bolsas em instituições estrangeiras, premiação de alunos que se destacam em provas e em suas condutas. Conforme o art. 20, as ações se concretizarão nas instituições em conjunto com as Organizações Sociais contratadas. Destaca, ainda, no art. 21 que é responsabilidade do Poder Executivo estabelecer a política de internacionalização, garantindo:

I - o fluxo contínuo de intercâmbio de professores, fomentando a pesquisa e uma melhor colocação nos índices e rankings internacionais;

II - a facilitação de reconhecimento de diplomas estrangeiros em instituições de ensino público ou privadas com alto desempenho, reconhecidas pelo MEC, possibilitando, inclusive, diplomas compartilhados na graduação e na pós graduação; e

III - a facilitação de acreditação de disciplinas cursadas em plataformas tecnológicas ofertadas por instituições de excelência no exterior (Brasil, 2020).

Segundo Giolo, Leher e Sguissardi (2020), essa proposta gerou indignação pelo modo simplista como foi apresentada ignorando as complexas ações já desenvolvidas nas IFES com relação às políticas de internacionalização, já que não se pode restringir a internacionalização à cursos de idiomas, intercâmbios de professores e de relações interinstitucionais. Além do mais parece vender algo simplificado que se apresenta como algo inquestionável, sem mostrar as consequências da proposta e nem os sentidos da internacionalização das IFES e, ainda, um aspecto de formalidade e operacionalidade relativo à internacionalização,

como

os intercâmbios, sem apresentar a própria política da internacionalização, seus objetivos e finalidades, em outras palavras, o espírito da internacionalização.

$\mathrm{Na}$ segunda versão, as ações apresentadas como internacionalização foram ampliadas, porém, continua sem representar a complexidade da internacionalização e o conjunto das ações que são realizadas nas IFES. Conforme Giolo et al. (2020) no mínimo deveria fazer referência às ações estruturantes para o desenvolvimento nacional, tais como propor ações de cooperação internacional destinadas a desenvolver centros de pesquisa e de desenvolvimento tecnológico, de aproveitamento da biodiversidade da Amazônia e da energia solar, dentre outros. Assim sendo, de acordo com Giolo et al. (2020) o Future-se concebe a internacionalização como "atividade de varejo imaginando que darão respostas por atacado". Em outras palavras, há um modismo em torno de algumas questões entre as quais a da internacionalização, sem compreensão (ou divulgação) do sentido da política de internacionalização e que relações estas estabelecem com a institucionalidade das IFES e de que maneira se interligam com outras questões como as levantadas pelos outros dois itens/eixos do Future-se, ou seja, a relação com 0 projeto em sua totalidade.

A terceira versão do Future-se não acrescenta nenhuma compreensão significativa em relação às anteriores. Busca-se definir internacionalização, entendendo como processo que envolve relações acadêmico-técnico-científicas 
com universidades internacionais, visando dar respostas aos problemas da sociedade globalizada, ou seja, aspectos superficiais, momentâneos, técnicos, institucionais etc., da internacionalização. Dentre outros aspectos, trata da dupla titulação, da diplomas e orientação conjunta de discentes. Embora não acrescente, apenas reduz ainda mais a relação das universidades nacionais com universidades internacionais, sem dizer com quais finalidades, com que tipo de investimento. $\mathrm{Na}$ realidade, trata de aspectos processuais e focais em determinadas ações, no âmbito das instituições e não dos problemas sociais. $A$ internacionalização é um dos três pilares do Future-se, no entanto, apesar do tratamento simplificado, mostra-se como uma isca para atrair atenção e adesão ao projeto Future-se como um todo, daí se infere que há uma concepção implícita e, que a concepção segue a mesma perspectiva mercantil do Future-se. Disso decorre, a prerrogativa de que as ações de internacionalização se tendem a se desenvolverem nas instituições universitárias em conjunto e com as mesmas relações das Organizações Sociais, atrelando o desenvolvimento do ensino e da pesquisas a interesses imediatamente mercantis, ao envolvimento de determinadas parcerias públicoprivadas, ao uso de espaços públicos (laboratórios e equipamentos) das IFES com empresas do setor privado e ao aproveitamento de pesquisadores $e$ laboratórios de pesquisa pra fins de produção de PD\&I para a iniciativa privada. Uma perspectiva plausível da internacionalização seria levantar possibilidades de relacionamento empresas e IFES, considerando que atualmente o investimento privado em PD\&I nas universidades brasileiras é bastante limitado com relação ao feito pelo poder público.

O fato mais importante, de cunho geral, é a redefinição ou redirecionamento do conceito de internacionalização, que já é uma prática conduzida nas IFES, agora numa perspectiva voltada para atender à privatização das Instituições Federais Públicas de Ensino Superior, isto é, o sentido da internacionalização é dado pelos outros dois eixos do Future-se.

$\mathrm{Na}$ apreciação das três versões do projeto Future-se evidencia-se a intenção maior de promover uma drástica mudança institucional, suprimindo a chamada autonomia universitária e introjetando valores predominantemente da racionalidade econômica e mercantil, justificadas globalmente por meio do eixo da internacionalização, afirmando as necessidades e demandas de um mundo globalizado. A intenção é alinhar os interesses público-acadêmico e até estratégico de Estado à interesses imediatamente capitalistas. A internacionalização, por sua vez, aparece como uma das vertentes ou eixos para promover a mudança institucional, permitindo a introdução mais efetiva dos interesses do setor privado nas IFES, criando uma aproximação entre as instituições de PD\&I e as IFES, e uma série de consequências, algumas ainda imprevisíveis, no âmbito do trabalho de produção de conhecimentos científicos e no âmbito da produção do conhecimento de caráter histórico e político. O Future-se 
é um programa não apenas perigoso para a identidade das universidades e institutos federais, mas estratégico no sentido criar uma onda nacional numa concepção de uma sociedade/economia do conhecimento universitário no cenário internacional.

\section{Considerações finais}

O objetivo deste artigo foi apresentar uma breve sistematização do programa Futurese, elaborado pelo MEC, em uma análise comparativa entre suas três versões, com destaque para o terceiro eixo, o menos detalhado pelo programa, referente à "internacionalização", além de apresentar algumas ponderações institucionais e posicionamentos de intelectuais que trataram do Future-se, buscando entender a concepção de educação superior, isto é, a institucionalidade das IFES com a possível implantação do Future-se e as implicações decorrente na dimensão internacional.

Apresentou-se um histórico do Future-se, sintetizando os três eixos nos quais se baseia, além de apresentar uma breve síntese das suas três versões. Em relação ao discurso oficial, o Future-se apresenta como seu objetivo promover maior autonomia financeira às universidades e institutos federais (IFES) por meio de incentivo à captação de recursos próprios e do empreendedorismo. Adicionalmente, ao discurso oficial do MEC discutiu-se a visão de estudiosos e entidades ligadas à educação expondo suas preocupações, críticas, e sugestões em relação ao Futurese. De modo geral, ressalta-se que as mudanças produzem alterações significativas na autonomia das IFES em decorrência das novas formas de gestão e de financiamento, com impactos diretos nas concepções de pesquisa, na natureza do trabalho dos professores, dentre outros. As mudanças no âmbito da gestão fortalecem a dimensão mercantil, com a introdução de práticas e parcerias empreendedoras e a inserção do setor privado interessados em investir e promover intercâmbio com as IFES, tendo estratégico aporte público por detrás das IFES.

Na perspectiva do eixo "internacionalização da educação" não se deve restringir somente aos aspectos estritamente pedagógicos e nem apenas ao mero intercâmbio ou relações internacionais entre instituições de ensino superior, mas considerar a sua inserção na economia de mercado internacional, sob a ótica da internacionalização do capital.

Enfim, os significados políticos e econômicos do programa Future-se são inúmeros, como observado por meio dos posicionamentos apresentados por estudiosos e representantes de diferentes entidades educacionais. De fato, o Futurese impõe uma drástica mudança na institucionalidade pública das instituições de ensino superior brasileiras, em termos de financiamento e de gestão universitária, revelando uma racionalidade mercantil internacional para se aproveitar dos aportes público-estatal, na produção de conhecimento acadêmico ligado ao cenário econômico em que a ciência e a tecnologia 
tornam-se instrumentos primordiais no desenvolvimento das forças produtivas e de aumento da lucratividade das empresas multinacionais, por meio da transferência da produção científica pública para a esfera da propriedade privada. É no âmbito dessa racionalidade que se pode explicar a concepção de internacionalização do audacioso projeto de reforma universitária.

Recebido em 26 de novembro de 2020 Aprovado em 17 de abril de 2021

\section{Referências}

Associação Nacional dos Dirigentes da Instituições Federais de Ensino Superior - ANDIFES (2019). Veja as manifestações de algumas Universidades Federais sobre o Programa Future-se. Disponível em: https://www.andifes.org.br/?p=65414. Acesso em: 23 de novembro de 2019.

Associação Nacional de Pós-Graduação e Pesquisa em Educação (ANPED). (2019). Nota da ANPED sobre a consulta pública referente a proposta FUTURE-SE do MEC. Disponível em: https://www.anped.org.br/news/nota-da-anped-sobre-consulta-publicareferente-proposta-future-se-do-mec. Acesso em 20 de outubro de 2019.

Baima, E. (2019) Future-se: destruição do ensino superior. Disponível em: https://otrabalho.org.br/future-se-destruicao-do-ensino-superior/. Acesso em 10 de novembro de 2019.

Brasil (2020). Projeto de lei que institui o Programa Universidades e Institutos Empreendedores e Inovadores - Future-se. Disponível em: https://www.in.gov.br/web/dou/-/despacho-236403674. Acesso em 02 de fevereiro de 2020.

Brasil (2019a). Consulta pública do Future-se é prorrogada até 29 de agosto. Brasilia: MEC. Disponível em http://portal.mec.gov.br/component/tags/tag/52641\%20. Acesso em 20 de setembro de 2019.

Brasil (2019b). Perguntas e respostas do Future-se, programa de autonomia financeira da educação superior. Brasília: MEC. Disponível em: http://portal.mec.gov.br/component/tags/tag/autonomia-financeira. Acesso em $11 \mathrm{de}$ dezembro de 2020.

Conselho Nacional das Instituições da Rede Federal de Educação Profissional, Científica e Tecnológica (CONIF). (2019). Nota oficial sobre o programa Future-se. Disponível em: https://portal.conif.org.br/images/1 82019 Nota Future-se Pleno.pdf. Acesso em 20 de agosto de 2019.

Dagnino, R., Romão, W., \& Bezerra, R. (2019). Universidades: Future-se e o aporte de recursos de empresas. Disponível em: https://diplomatique.org.br/Future-se-e-o-aportede-recursos-de-empresas/.Acesso em: 05 de novembro de 2019. 
Giolo, J., Leher, R., \& Sguissardi, V. (2020). Future-se: ataque à autonomia das instituições federais de educação superior e sua sujeição ao mercado. Disponível em: https://www.diagramaeditorial.com.br/project/Future-se/. Acesso em: 20 de dezembro de 2020.

Grupo de Pesquisa Trabalho, Precarização e Resistências. Centro de Estudos e Pesquisas em Humanidades/CRH-UFBa. (2019). FUTURE-SE: uma análise preliminar da administração da Universidade Federal de Pelotas. Disponível em: https://ccs2.ufpel.edu.br/wp/wp-content/uploads/2019/07/Future-se-Analise-UFPel.pdf. Acesso em 11 de novembro de 2019.

Leher, R. (2019). Análise preliminar do Future-se.Disponível em: https://avaliacaoeducacional.files.wordpress.com/2019/07/sobre-o-Future-se-notasprelim-rleher-24-07pdf.pdf. Acesso em 26 de novembro de 2019.

Marques, L. (2019). Academia Brasileira de Educação declara apoio formal ao Future-se. Disponível em: http://portal.mec.gov.br/component/content/212-noticias/educacaosuperior-1690610854/80371-academia-brasileira-de-educacao-declara-apoio-formalao-Future-se. Acesso 26 de novembro de 2019.

Minto, L. W. (2019). O Future-se quer tornar o Ensino Superior produto de luxo. Disponível em: https://www.esquerdadiario.com.br/O-Future-se-quer-tornar-o-Ensino-Superiorproduto-de-luxo-Entrevista-com-Lalo-Watanabe. Acesso em 13 de novembro de 2019.

Moreno, A. C. (2019). MEC reformula proposta do Future-se e diz que lançará nova consulta $\begin{array}{lllll}\text { pública } & \text { até } & 0 & \text { dia } & \text { Disponível em: }\end{array}$ https://g1.globo.com/educacao/noticia/2019/10/18/mec-reformula-proposta-do-futurese-e-diz-que-lancara-nova-consulta-publica-ate-o-dia-28.ghtml. Acesso em 12 de novembro de 2019.

Rede Brasil Atual. Future-se fere o princípio da autonomia universitária, previsto na Constituição. (2019). Disponível em: https://www.redebrasilatual.com.br/educacao/2019/11/Future-se-fere-o-principio-daautonomia-universitaria-previsto-na-constituicao/. Acesso em: 20 de novembro de 2019.

Sindicato Nacional dos Servidores Federais da Educação Básica, Profissional e Tecnológica - SINASEFE IFSul (2019). FUTURE-SE: Após críticas, governo "reformula" proposta e abre nova consulta pública. Disponível em: http://www.sinasefeifsul.org.br/noticias/Future-se-apos-criticas-governo-reformulaproposta-e-abre-nova-consulta-publica/1979/ Acesso em 14 de novembro de 2019.

Taffarel C. N. Z., \& Sousa E. C. C. (2019). Dossiê: considerações sobre o plano nacional de educação: a política de formação dos profissionais da educação e o programa institutos $e$ universidades empreendedoras e inovadoras (Future-se). Disponível em: https://www.anfope.org.br/wp-content/uploads/2019/08/DOSSIÊ-CONSIDERACCÕESFUTURE-SE-ANFOPE-1-compactado.pdf. Acesso em 10 de novembro de 2019.

Universidade Federal de Pelotas - UFPel (2019). Future-se: uma análise preliminar da administração da Universidade Federal de Pelotas. Disponível em: https://ccs2.ufpel.edu.br/wp/wp-content/uploads/2019/07/Future-se-Analise-UFPel.pdf Acesso em 11 de novembro de 2019. 